\title{
The influence of lipids on the fate of nitrogen during hydrothermal liquefaction of protein-containing biomass
}

\author{
Y. Fan ${ }^{\mathrm{a}, *}$, U. Hornung ${ }^{\mathrm{a}, \mathrm{b}}$, K. Raffelt ${ }^{\mathrm{a}}$, N. Dahmen ${ }^{\mathrm{a}}$ \\ ${ }^{a}$ Karlsruhe Institute of Technology, Institute of Catalysis Research and Technology (IKFT), Karlsruhe, Germany \\ ${ }^{\mathrm{b}}$ University of Birmingham, School of Chemical Engineering, Edgbaston, Birmingham, B15 2TT, United Kingdom
}

A B S T R A C T

Keywords:

HTL

Nitrogen

Lipids

Proteins

Maillard reactions

\begin{abstract}
Hydrothermal liquefaction (HTL) of carbohydrate (lactose), protein (lysine), and lipid (palmitic acid) surrogates was carried out in batch reactors for $20 \mathrm{~min}$ in a temperature range of $250-350{ }^{\circ} \mathrm{C}$ in order to understand interactions in hydrothermal reactions. A binary mixture of lysine and lactose leads to a higher bio-oil yield when compared to experiments made with isolated compounds, indicating a relevant contribution by Maillard reactions (MRs). Emulsification happens to proteins and lipids during HTL, making it difficult to separate and collect bio-oil products at low temperatures. When testing the ternary mixture, the nitrogen content of the bio-oil is negligibly affected by the changes of temperature, presenting a constant value of $5.3 \mathrm{wt}$. \% . However, adding lipids dramatically changes the bio-oil composition. This is indicated by an increasing amount of fatty acid amides and a decrease in Maillard reaction products, suggesting a strong competition between amidation and MRs. A reaction scheme was proposed based on the final products and assumed reaction pathways. These findings here can contribute to a better understanding of the HTL of biomasses with complex organic compositions.
\end{abstract}

\section{Introduction}

Hydrothermal liquefaction (HTL) has been recently considered a promising technology to convert biomass and waste into energy, as it is able to convert wet feedstocks into liquid fuel precursors without the need for drying. Therefore, it is an attractive technology for wet biomass including food waste [1,2], algae [3,4], and sewage sludge [5,6], which include mixtures of organic and inorganic components, and have been widely studied as feedstocks to produce fuel-like products, including bio-oil, biochar, biogas, and platform chemicals. However, when considering protein-containing biomasses as feedstocks, the effect of the heteroatom nitrogen $(\mathrm{N})$ in the bio-oil cannot be ignored when thinking about a possible future commercial utilization.

Bio-oil generally features a high nitrogen content (0.3-9\%), depending on the feedstock [7]. $\mathrm{N}$ in bio-oil is undesired because it not only produces NOx during combustion, but also leads to high viscosity and decreases the stability of bio-oil during storage due to crosslinking/oligomerization reactions $[8,9]$. Therefore, considerable works have been focused on the promising methods to obtain nitrogen-free bio-oil by liquefaction.

Duan et al. [10] have reported the effects of heterogeneous catalysts on HTL of algae. All these catalysts effectively lead to a bio-oil with a lower proportion of $\mathrm{N}$ than the starting feedstock, decreasing from 6.32 to $3.74 \mathrm{wt} . \%$, indicating that $\mathrm{Ru} / \mathrm{C}$ and $\mathrm{Ni} / \mathrm{SiO}_{2}-\mathrm{Al}_{2} \mathrm{O}_{3}$ are capable of providing in situ denitrogenation during liquefaction. Posmanik et al. [2] elucidated the effect of adding acid and alkali to HTL of manure digestate and food waste. They found that alkaline conditions resulted in lower $\mathrm{N}$ contents in the bio-oil, albeit not declining below $3 \mathrm{wt} . \%$ in the oil from both feedstocks.

Qian et al. [11] compared the influence of heating procedures on the bio-oil compositions from isothermal $(673 \mathrm{~K}, 60 \mathrm{~min})$ and fast (773 K, $1 \mathrm{~min}$ ) HTL of sewage sludge. Bio-oil produced from fast HTL features a lower N/C ratio than the one obtained from isothermal HTL, while longer reaction times result in a higher concentration of $\mathrm{N}$-containing compounds in the bio-oil. This suggests that only adjusting the condition parameters and adding catalysts is not enough to achieve complete $\mathrm{N}$ removal. Despite the existence of bio-oil upgrading treatments such as hydrotreating [12] and distillation [13], which could reduce the $\mathrm{N}$ content in the bio-oil, these are extremely cost-intensive processes, especially the former, due to their employment of $\mathrm{H}_{2}$. Moreover, bio-oil obtained from HTL can contain water, which is difficult to remove during solvent extraction, being one of the mentioned causes for deactivation of upgrading sulfide catalysts $[8,14,15]$. Hence, it is still necessary to clarify the behavior of nitrogen in liquefaction.

\footnotetext{
* Corresponding author.

E-mail address: yujie.fan@partner.kit.edu (Y. Fan).
} 
To evaluate the influence of the complex feedstock on the fate of $\mathrm{N}$, HTL experiments are often conducted with model compounds to simplify the reaction pathways. For example, Teri et al. [16] studied hydrothermal conversion of model compounds (corn starch, cellulose, soy protein, albumin, sunflower oil and castor oil) in a small-scale system, and found a significant difference among model compounds in terms of the influence of different conditions, the $\mathrm{N}$ content in the bio-oil being nearly reduced in half. However, less information is reported about the interactions between model compounds. Posmanik et al. [17] performed HTL of model compounds (starch, bovine serum albumin, and linoleic acid-and their binary and ternary mixtures) into bio-oil at different temperatures and retention times. The authors revealed the influence of interactions that occur between these different model compounds based on the change of yields, elemental compositions, and higher heating values (HHVs) of the bio-oil obtained from HTL. Still, information regarding chemical compositions in the bio-oil affected by the interactions is missing; a deeper investigation is needed.

Maillard reactions (MRs) are well-confirmed as important interactions during HTL [18-21]. These are caused by a reaction of the amine group of amino acids with the carbonyl group present in carbohydrates. This reaction leads to higher bio-oil yields, but also to a decrease in the quality due to an increasing $\mathrm{N}$ content. In our previous work [22], disaccharides and amino acids were selected as model carbohydrates and protein to systemically investigate the influence of MRs on the fate of $\mathrm{N}$ as well as the $\mathrm{N}$-containing compounds in the bio-oil at different temperatures. The occurrence of MRs undesirably results in a higher $\mathrm{N}$ content in the bio-oil along with more N-containing heterocycles.

In a complex biogenic feedstock, carbohydrates and proteins are not the only two typical organic compositions, as lipids are another dominant part. Therefore, the influence of lipids on the fate of $\mathrm{N}$ is significant for demonstrating the reaction mechanism of the $\mathrm{N}$ transformation. This is because the amide formation is also regarded as undesired as it adds to the $\mathrm{N}$ content in the bio-oil and decreases the fatty acid yields [23,24]. To some extent, this reaction can compete with MRs, to modify the $\mathrm{N}$ content along with the specific $\mathrm{N}$-containing compounds in the bio-oil. However, among the aforementioned hydrothermal reaction studies using model compounds, relatively limited information is available regarding the effects of lipids on the chemical components of the oil. In this sense, to have a full grasp of the distribution of $\mathrm{N}$ during HTL, it is paramount to include the presence of lipids in the mixture.

As co-liquefaction of different organic materials is becoming more attractive, knowing the effects of the possible interactions between different chemical compounds can become of great future value to produce high yields of high-quality oils [25-27]. The investigation of ternary mixtures can be used to evaluate their potential bio-oil production via co-liquefaction. Furthermore, lipid extraction from waste biomass to be used for biodiesel increasingly becomes the focus of research $[28,29]$. How to effectively deal with the residues after extraction will most likely become a new challenge. The investigation of the influence of lipids on the fate of $\mathrm{N}$ after HTL will provide new information to help estimate the feasibility of this waste management pathway.

In the current study, lactose (lac) was chosen because it is a strongly reducing disaccharide widely occurring in natural products. Lysine (lys) is known to be the most reactive amino acid in the Maillard reactions due to the presence of two reactive amino groups [22]. In order to determine the effects of lipids on the fate of $\mathrm{N}$, particularly in regard to the N-containing heterocyclic compounds, lactose and lysine were selected and supposed to undergo relatively active Maillard reactions, which helps to quantify the specific components in the obtained bio-oil. Palmitic acid (PA) was selected as model fatty acid as it has been widely confirmed as the major fatty acid in lipid-rich biomass [20,30].

The specific objectives of this work are, firstly, to investigate the effects of lipids on the fate of N during HTL; secondly, to reveal the change of N-containing compounds in the bio-oil after HTL of different matrices at different temperatures, and, finally, to determine the possible reaction pathways based on the influence of temperatures. The results of the study are expected to fill the gap by providing detailed information regarding $\mathrm{N}$ transformation from protein and lipid-derived feedstock under HTL conditions to convey a better fundamental understanding of the mechanisms of the production of bio-oil from real biomass.

\section{Materials \& methods}

\subsection{Materials}

The model compounds used in this study, i.e., palmitic acid, lactose, and lysine, were of analytical grade and purchased from Sigma-Aldrich. HPLC- (High Performance Liquid Chromatography) grade dichloromethane (DCM) and tetrahydrofuran (THF) purchased from Sigma-Aldrich were used for the bio-oil recovery from the reaction vessel. Piperidine, 2,5-dimethylpyrazine, 2,3,5-trimethylpyrazine, and palmitamide were purchased from Alfa Aesar, and caprolactam was purchased from Sigma-Aldrich.

\subsection{Hydrothermal liquefaction}

The feedstocks were liquefied in micro-autoclaves with a volume of $24.5 \mathrm{ml}$ made of stainless steel alloy 1.4571, which can withstand pressures of up to $40 \mathrm{MPa}$ and a maximum temperature of $400{ }^{\circ} \mathrm{C}$. Each batch was constituted by $10 \mathrm{wt}$. \% of feedstock that was dissolved in distilled water and filled into the reactor. For the binary mixture tests, the feedstock was a 50:50 wt. \% mixture of lysine and lactose, whereas for the ternary mixture, the feedstock was a 1:1:1 w/w mixture of PA, lactose, and lysine. The micro-autoclaves were flushed by using nitrogen gas to sweep away the undesired air and then pressurized to $2 \mathrm{MPa}$ before closing it with a torque key. The micro-autoclaves were then introduced in a gas chromatography (GC) furnace that allowed controlling the reaction temperature. Heating was performed at a heating rate of $40^{\circ} \mathrm{C} / \mathrm{min}$ and kept at the target temperature within the $250-350^{\circ} \mathrm{C}$ range for $20 \mathrm{~min}$. After the reaction, the autoclaves were taken out of the oven and put into cold water to cool down and to stop the reaction. The cooling time depends on the reaction temperature and varies from 15 to $20 \mathrm{~min}$.

\subsection{Sample separation and analysis}

After reaction, the micro-autoclaves were opened in a gas-tight containment and purged with nitrogen. More details about the special opening device are given in a previous publication [4]. The gas composition was measured by manually injecting $100 \mu \mathrm{L}$ of the gas sample in an Agilent 7890A gas chromatograph (equipped with a $2 \mathrm{~m}$ Molsieve $5 \AA$ and $2 \mathrm{~m}$ Porapak Q column). The mixture products including aqueous phase (AQ), bio-oil, and solid residue (SR) were filtered by vacuum filtration using a Whatman nylon membrane $(47 \mathrm{~mm}, 0.45 \mu \mathrm{m}$ pore size). Most of the bio-oil and solid residue remained sticking on the micro-autoclave walls after reaction, hence abundant use of DCM was required to maximize the recovery of products. The solid residue remaining in the filter was placed in an oven and dried overnight at $105^{\circ} \mathrm{C}$ to determine the dry weight. The bi-phase mixture obtained (aqueous product plus bio-oil) was centrifuged and separated. The organic solvent was evaporated by flushing with nitrogen for $24 \mathrm{~h}$. Once a constant weight was achieved, it was recorded and considered as the bio-oil mass.

\subsection{Characterization of products}

The $\mathrm{C}, \mathrm{H}$, and $\mathrm{N}$ contents of the bio-oil and the solid residue were measured by elemental analysis (Vario EL III, Elementar Analysensysteme $\mathrm{GmbH}$, Hanau, Germany), with the $\mathrm{O}$ content being 
calculated by difference. The elemental measurements are checked for deviations by 10 times measurement for one representative bio-oil sample. The statistical errors of $\mathrm{C}, \mathrm{H}$, and $\mathrm{O}$ were $0.45,3.03$, and 0.69 $\%$, respectively.

GC-MS analysis of bio-oil was carried out using an Agilent $6890 \mathrm{~N}$ gas chromatograph with an Agilent 5973 MSD mass spectrometry detector and a DB-5 capillary column $(30 \times 0.25 \mathrm{~mm} \times 0.25 \mu \mathrm{m})$ after diluting with THF $(1: 1 \mathrm{ml} / \mathrm{ml})$ and filtering with a $0.20 \mu \mathrm{m}$ polytetrafluoroethylene (PTFE) filter. Compound identification of the main peaks was performed using a NIST mass spectral database, considering only molecules with a match quality above $60 \%$. The amount of the different compounds was estimated by the relative area percentage method, namely, the relative peak area of an individual compound divided by the total peak area of all identified components. The quantitative analysis of selected chemicals (previously identified by GC-MS) is measured by GC-FID with an Agilent DB- 5 capillary column $(30 \times 0.25 \mathrm{~mm} \times 0.25 \mu \mathrm{m})$. For the quantitative testing, the oven column temperature was kept at $80^{\circ} \mathrm{C}$ for $2 \mathrm{~min}$, held at $175^{\circ} \mathrm{C}$ for $5 \mathrm{~min}$. after ramping at $5 \mathrm{~K} / \mathrm{min}$, and held at $250{ }^{\circ} \mathrm{C}$ for $8 \mathrm{~min}$ after ramping at $30 \mathrm{~K} / \mathrm{min}$.

The total carbon (TC), total inorganic carbon (TIC) and total nitrogen (TN) in aqueous phase were measured by a Dimatec ${ }^{\circledR} 2100$ instrument. Ammonium $\left(\mathrm{NH}_{4}{ }^{+}\right)$, and Nitrate $\left(\mathrm{NO}_{3}{ }^{-}\right)$and nitrite $\left(\mathrm{NO}_{2}{ }^{-}\right)$ were investigated using a Metrohm 838 advanced sample processor device.

\subsection{Data analysis}

The yields of different product fractions were calculated as the ratio of the weight of the recovered mass of the product $\left(M_{p i}\right)$ and the total mass of feedstock, see Eq. (1).

Products Yields (wt. \%) $=\frac{M_{p i}}{M_{f}} \times 100$

The elemental distribution, namely nitrogen distribution (ND), is defined as the amount of an element in the product $\left(m_{E i}\right)$ relative to that in the feedstock $\left(m_{E f}\right)$, see Eq. (2).

Elemental Distribution (wt. \%) $=\frac{m_{E i}}{m_{E f}} \times 100$

The energy recovery (ER) as the fraction of the high heating value in the recovered bio-oil $\left(H H V_{B O}\right)$ divided by that value $\left(H H V_{f}\right)$ in the feedstock, see Eq. (3). $\mathrm{Y}_{\mathrm{BO}}$ represents the yields of bio-oil,

Energy Recovery $(\%)=\frac{Y_{B O} \times H H V_{B O}}{H H V_{f}} \times 100$

In this work, the uncertainty, namely, the loss of recovery, is due to the remaining products stuck to the micro-autoclave walls after reaction, and the loss of volatile compounds (during extraction solvent removal), water formation, and experimental errors. To confirm the reproducibility and comparability of results, experiments were carried out in duplicates. Each data point was represented as the average of the two independent experiments, with an error corresponding to its standard deviation. In the case that the deviation was above $10 \%$ between the two data sets, the experiment was repeated.

\section{Results}

\subsection{Bio-oil products}

The bio-oil yield obtained from HTL of single, binary, and ternary mixtures is displayed in Fig. 1. Regarding isolated components, PA presents the most potential bio-oil products, around 10 times higher than that from isolated lysine and lactose under the same conditions. All bio-oil yields considerably increase with rising temperature, except

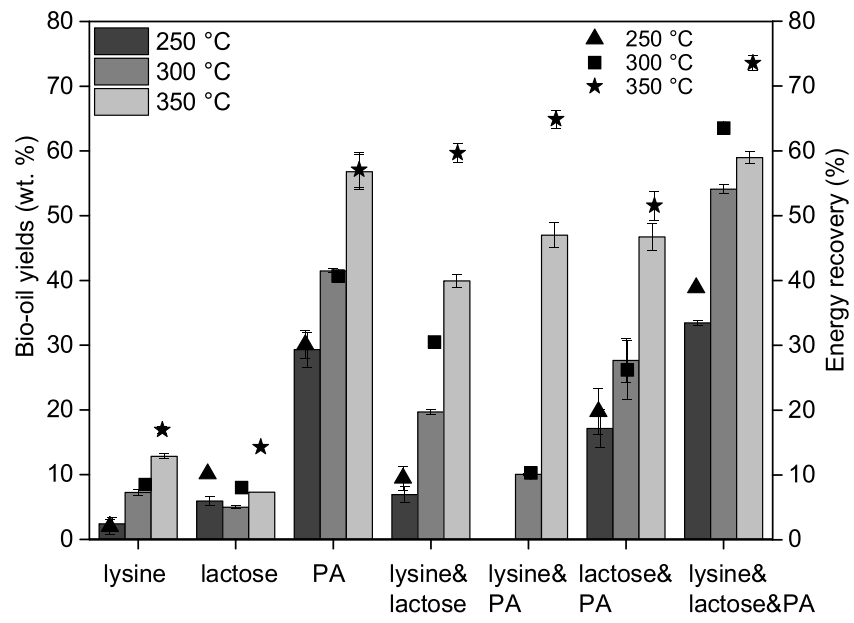

Fig. 1. The bio-oil yields and energy recovery from HTL of model compounds at three different temperatures (bio-oil products from lysine mixed with PA at $250^{\circ} \mathrm{C}$ were not collected).

in the case of lactose, which shows a low dependency on the temperatures, for which a maximum of $7 \mathrm{wt}$. $\%$ was obtained at $350{ }^{\circ} \mathrm{C}$. Regarding HTL of lysine, the bio-oil yield obtained increases from 2.4 to $12.8 \mathrm{wt}$. \% when the temperature rises from 250 to $350^{\circ} \mathrm{C}$. In all binary mixture cases, the results show a significant increase in the bio-oil yield with temperature, although one must notice that the bio-oil from HTL of lysine and PA at $250^{\circ} \mathrm{C}$ is missing, due to the difficult separation from the aqueous phase (see the sample picture in $\mathrm{S} 1$ ). Compared to lysine mixed with PA at $300^{\circ} \mathrm{C}$, higher bio-oil yields are obtained from HTL of lactose and PA mixture. Notably, ternary mixtures produce much more bio-oil with yields increasing from 33.4 to $60 \mathrm{wt}$. \% when the temperature increases from 250 to $350{ }^{\circ} \mathrm{C}$.

Energy recovery (ER) is also shown in Fig. 1. Concerning the isolated model compound, the highest energy recovery (ER) is obtained in bio-oil from HTL of PA, while the lowest is in bio-oil from HTL of lysine at $250^{\circ} \mathrm{C}$. Considering binary mixtures, higher ER are achieved from HTL of lysine mixed with lactose; under the same conditions, lactose mixed with PA results in lesser ER compared with single PA, recovering the smallest ER at $350^{\circ} \mathrm{C}$. After HTL of ternary mixtures, ER is significantly increased from 40 to $74 \%$ with rising temperature.

\section{2. $N$ content and distribution in the bio-oil}

As we mentioned in the experimental section, the initial feedstock concentration was fixed at $10 \mathrm{wt}$. \%, which means that the relative lysine contents in the binary and ternary mixtures are only half and one third of that in the single lysine sequence (Details are listed in Table S4). Therefore, the starting $\mathrm{N}$ content is different as shown in Fig. 3 with square plot, going from 19.2, 9.6, and $6.4 \%$ for lysine, binary and ternary mixtures, respectively. In order to compare the effect of different compounds on the $\mathrm{N}$ transformation to bio-oil, the $\mathrm{N}$ distribution was introduced as defined by Eq. (2). Seeing that, after HTL of lysine alone, the $\mathrm{N}$ content dramatically drops, decreasing from 16.6 to $10 \mathrm{wt}$. $\%$ with the increasing temperatures. The reduction is also enhanced by reaction temperature, from 13.5 to $47.9 \%$. When mixed with lactose, compared with single lysine, a similar trend on the temperature dependency can be found. The $\mathrm{N}$ content in the bio-oil gradually decreases with increasing temperature, but the difference of $\mathrm{N}$ content between feedstock and bio-oil, which is also called reduction, is smaller than that from HTL of lysine alone. At $250^{\circ} \mathrm{C}$, the $\mathrm{N}$ content in the bio-oil is even higher than that of initial feedstock, reaching to the similar value at $300{ }^{\circ} \mathrm{C}$, then a bigger drop at $350^{\circ} \mathrm{C}$. Regarding the mixtures of lysine and palmitic acid, even though the results at $250^{\circ} \mathrm{C}$ are missing, it 

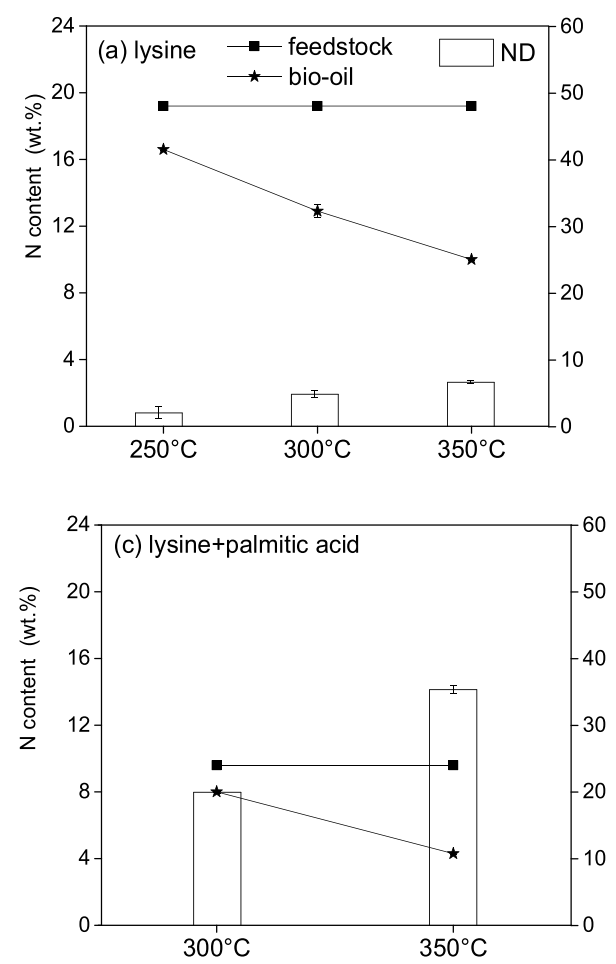
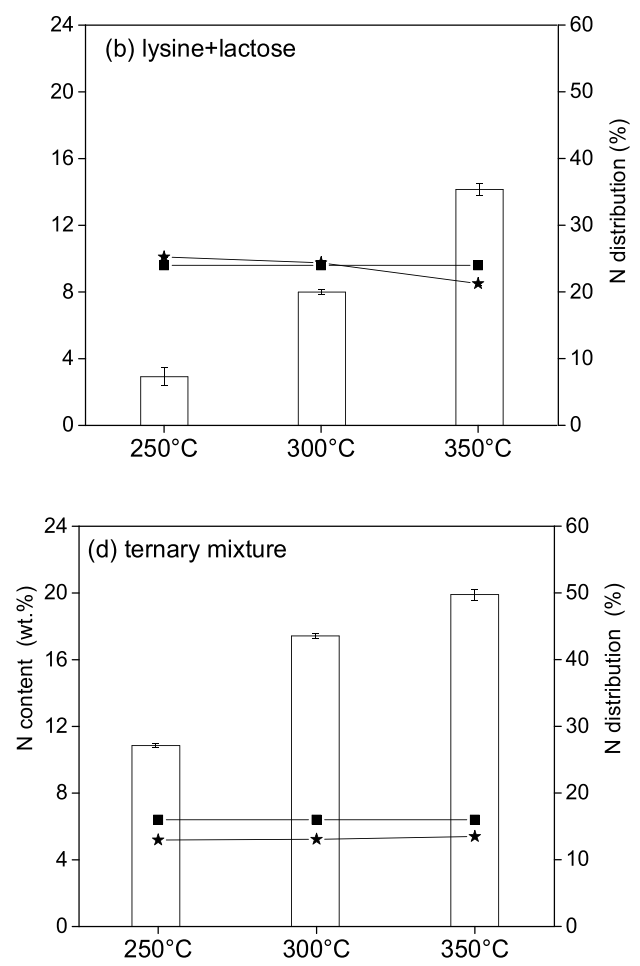

Fig. 2. Comparison of $\mathrm{N}$ content (represented by data points) and $\mathrm{N}$ distribution (represented by bars) in the bio-oil obtained from (a) lysine; (b) lysine mixed with lactose; (c) lysine mixed with palmitic acid; (d) ternary mixture at different temperatures.

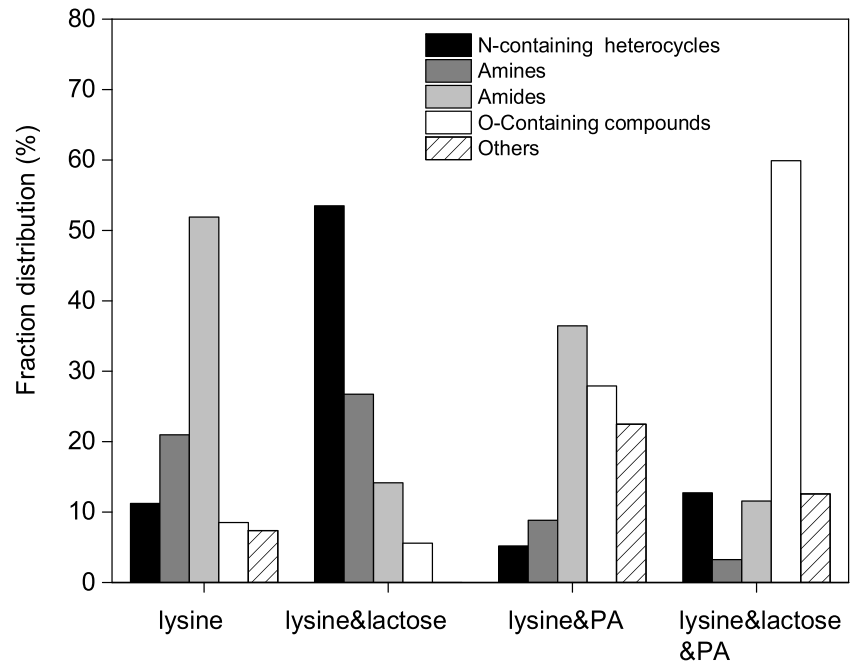

Fig. 3. Comparison of compounds identified by GC-MS analysis of bio-oil from HTL of model compounds at $300{ }^{\circ} \mathrm{C}(20 \mathrm{~min})$ based on fraction distribution (\%); $\%$ means relative peak area $\%$.

seems like the $\mathrm{N}$ content in the bio-oil is decreased with increasing temperature, with a reduction of nearly $50 \%$ at $350^{\circ} \mathrm{C}$ compared to the value at $300^{\circ} \mathrm{C}$. Fig. 2 (d) shows the $\mathrm{N}$ content in the bio-oil from HTL of ternary mixtures, which is quite stable, a slight increase from 5.2 to 5.4 wt. \% when the temperature rises from 250 to $350^{\circ} \mathrm{C}$, with a reduction of $18 \%$ from the initial $\mathrm{N}$ content in the feedstock. The $\mathrm{N}$ distribution (Fig. 2) significantly increases with reaction temperatures in all the cases. Under the same conditions, unlike $\mathrm{N}$ content, ternary mixtures show the highest $\mathrm{N}$ distribution, followed by lysine and lactose mixture, then palmitic and lysine mixture, and single lysine, despite the fact that bio-oil produced from lysine contains the highest amount of $\mathrm{N}$ content.

\subsection{Chemical compositions in the bio-oil}

GC-MS analysis was used to identify the organic compounds in the bio-oil. The bio-oil is a complex mixture, and hundreds of peaks were displayed in the total ion chromatograms. To ease the discussion, the major chemical compounds in the bio-oils were classified into five categories based on relevant functional groups: $\mathrm{N}$-containing heterocycles (e.g., pyridines and pyrazines), amines (e.g., cyclic piperidines, and 2,4,6-trimethyl-benzenamine), amides (e.g., caprolactam and palmitamide), O-containing compounds (mostly palmitic acid in the case that PA is involved in the feedstock), and others which represents the undetected compounds.

As illustrated in Fig. 3, the fractions identified in the bio-oil are largely dependent on the feedstock. The lysine bio-oil contains a large fraction of cyclic amides, which is dramatically decreased (reduction of $73 \%$ ) in the bio-oil obtained from the mixture with lactose, whereas $\mathrm{N}$ containing heterocycles increase from around $10 \%$ to $54 \%$. Considering the binary mixture of lysine and palmitic acid, the amide content is lower compared to the lysine HTL product, though the amides are the group with the highest amount (36\%). A high fraction of palmitamide (3.46\%) must be mentioned, which reflects the direct interaction between lysine and PA; the highest fraction of "Others" is met for this situation (22.5\%). Regarding the ternary mixture, $59 \%$ of the product belongs to the O-containing compounds including $57 \%$ non-reacted palmitic acid, and similar amounts of N-cyclic heterocycles and amides are obtained from ternary mixture (around $12 \%$ ).

The key compounds identified by GC-MS are also quantified and shown in Fig. 4. The yields of specific products are defined as the mass of individual compounds based on the mass of total bio-oil. Piperidine and caprolactam are the two main N-containing compounds detected from HTL of lysine alone, which has been published already in an earlier paper [22], representing cyclic amine and amide. As shown in Fig. 4(a), both compounds first dramatically increase and then decrease with increasing temperature from 250 to $350{ }^{\circ} \mathrm{C}$, while the yields of caprolactam are nearly twice that of piperidine at the same temperature. However, when mixed with lactose (Fig. 4(b)), new N-cyclic 

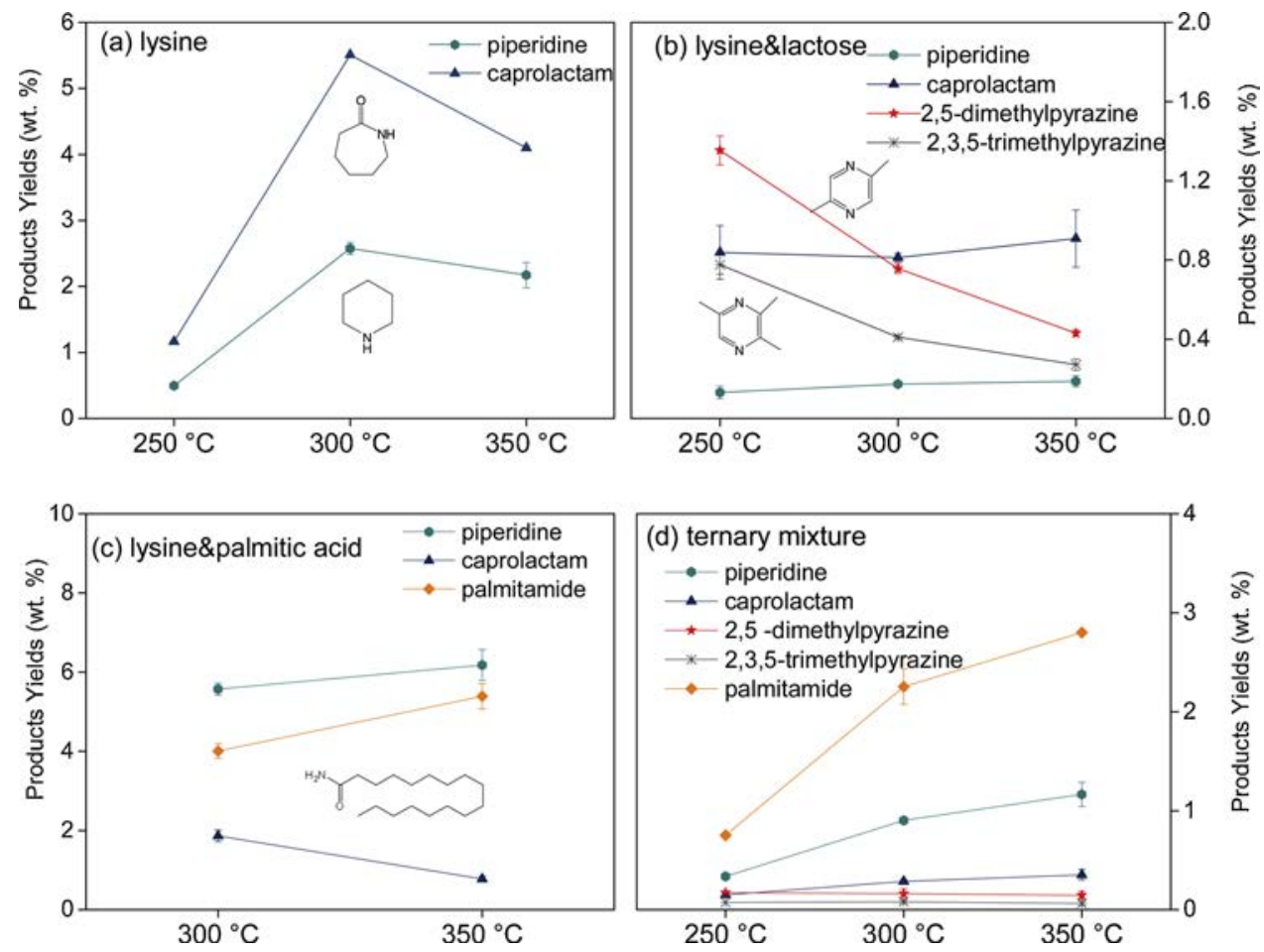

Fig. 4. Key N-containing compounds in the bio-oil obtained from HTL of model compounds (a) single lysine; (b) lysine and lactose mixtures; (c) lysine and palmitic acid; (d) ternary mixture.

heterocycles (pyrazine derivatives) are present at a big expense of the latter two. Less than $0.4 \mathrm{wt}$. \% of piperidine is found in the bio-oil, slightly more as the temperature increases. Caprolactam is leveled off with reaction temperature, reaching to $0.8 \mathrm{wt}$. $\%$ at $350^{\circ} \mathrm{C}$, which is 5 times less than that from the product of single lysine. Pyrazines are almost linearly reduced with increasing temperature. Considering the mixture of lysine and palmitic acid (Fig. 4(c)), firstly, we can clearly see that in contrast to single lysine, higher yields of piperidine are found in the bio-oil, around triple that of caprolactam. And the yields of piperidine slightly increased to $7.5 \mathrm{wt} \%$ at $350^{\circ} \mathrm{C}$. Palmitamide is identified as a new N-containing amide, increasing from 3.8 to $5.7 \mathrm{wt}$. \% when the temperature rises from 300 to $350{ }^{\circ} \mathrm{C}$. Accordingly, a decrease in caprolactam from 1.7 to 0.7 wt. \% is observed. Regarding ternary mixtures (Fig. 4(d)), palmitamide and piperidine become the major $\mathrm{N}$ containing compounds, increasing from 0.8 to $2.8 \mathrm{wt}$. \% and 0.3 to $1.3 \mathrm{wt}$ \% $\%$ respectively. $0.1 \mathrm{wt}$ \% 2,3,5-trimethylpyrazine and $0.2 \mathrm{wt}$ \% 2,5-dimethylpyrazine are obtained in the bio-oil, $0.3 \mathrm{wt}$. \% caprolactam is found at all temperatures.

\subsection{Nitrogen distribution in the product phases}

Fig. 5 illustrates the nitrogen distribution (ND) in the different product phases. Fig. 5(a) shows the ND in the bio-oil, solid residue (SR), and aqueous phase (AQ) according to Fig. 2(a-d). Compared with lysine, the ND to bio-oil is increased with the addition of lactose and palmitic acid, and significantly rises with the reaction temperature. Accordingly, a slight decrease in ND can be observed in the AQ from HTL of lysine. Considering the binary and ternary mixtures, the ND to $\mathrm{SR}$ and $\mathrm{AQ}$ are dramatically reduced with increasing temperature. In particular, the ND to SR obtained from binary and ternary mixture of lactose decreased from 17.6 to $3.1 \%$ and 12.5 to $1.1 \%$, respectively. Furthermore, it is notable to see that around $35 \%$ (in the AQ from ternary at $350{ }^{\circ} \mathrm{C}$ ) to $70 \%$ (in the $\mathrm{AQ}$ from lysine alone at $250{ }^{\circ} \mathrm{C}$ ) are converted into water phase. Therefore, a specific investigation of ND in $\mathrm{AQ}$ is displayed in Fig. 5(b). The N in AQ is classified into ammonium $\left(\mathrm{NH}_{4}{ }^{+}-\mathrm{N}\right)$ and organic nitrogen, which is calculated by the difference between total nitrogen and ammonium. In all the cases, the $\mathrm{NH}_{4}{ }^{+}-\mathrm{N}$ is sharply increased by increasing temperature, almost reaching to $80 \%$ in the AQ from binary and ternary at $350{ }^{\circ} \mathrm{C}$. In the presence of lactose and $\mathrm{PA}, \mathrm{NH}_{4}{ }^{+}-\mathrm{N}$ distribution is higher than that from lysine alone.

\section{Discussion}

From Fig. 2, we can see that, in the case of single lysine and binary mixture with lactose and PA, a decrease in the nitrogen content with a rising temperature is observed, owing to the fact that amino acid nitrogen compounds tend to form water-soluble components, which are partitioned into aqueous phase. However, the ND to bio-oil phase is significantly increased with rising temperature, this can be explained by the higher yields of bio-oil as shown in Fig. 1, which compensate the decrease in N content. Regarding HTL of lysine, at $250{ }^{\circ} \mathrm{C}, 70 \% \mathrm{~N}$ distributes into the $\mathrm{AQ}$, with a percentage of $11 \% \mathrm{NH}_{4}{ }^{+}-\mathrm{N}$, indicating that the deamination rate of lysine is slower at lower temperature. The major N-containing compounds in the bio-oil are piperidine and caprolactam, suggesting that lactamization and cyclization are the reaction routines during HTL, specific reaction pathways can be found in the previous work [22]. When mixed with lactose, MRs occur via HTL at $250{ }^{\circ} \mathrm{C}$, as the evidence of more oil-soluble pyrazines are formed along with the decrease of lysine-derived products, resulting in a higher nitrogen content in the bio-crude, compared to the starting $\mathrm{N}$ content in the feedstock. With increasing temperature, pyrazines and caprolactam are decreased, as a result of decreasing $\mathrm{N}$ content in the bio-oil.

Koehler et al. [31] reported that pyrazine rapidly increased with rising temperatures for temperatures of up to $150{ }^{\circ} \mathrm{C}$, but the results shown in Fig. 4(b) seem to contradict this, indicating the degradation of these molecules instead; the gap of temperature between $150-250{ }^{\circ} \mathrm{C}$ must be considered when comparing the values. However, it must be kept in mind that Koehler reported the values in feedstock basis, whereas Fig. 4(b) refers to an oil basis.

Palmitic acid is a saturated fatty acid, and can be regarded as a biooil owing to the extraction by DCM. The palmitic acid concentrations in the bio-oil, namely, the mass of PA based on the mass of total bio-oil, 

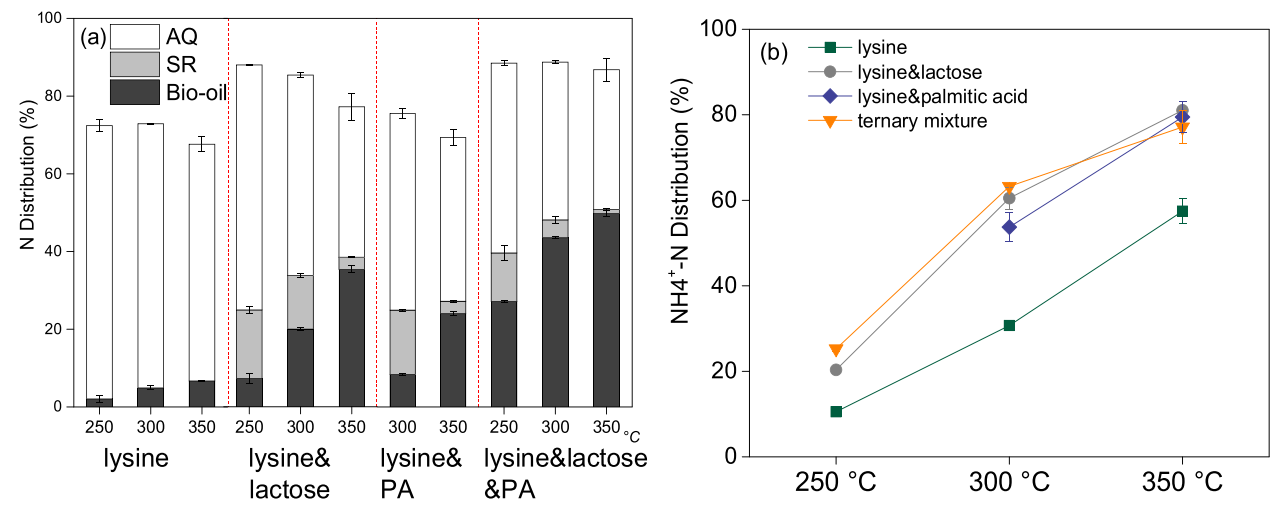

Fig. 5. (a) Nitrogen distribution to different product phases; (b) $\mathrm{NH}_{4}{ }^{+}-\mathrm{N}$ distribution to aqueous phase ( $\mathrm{AQ}$ and SR represent aqueous phase and solid residue, respectively).

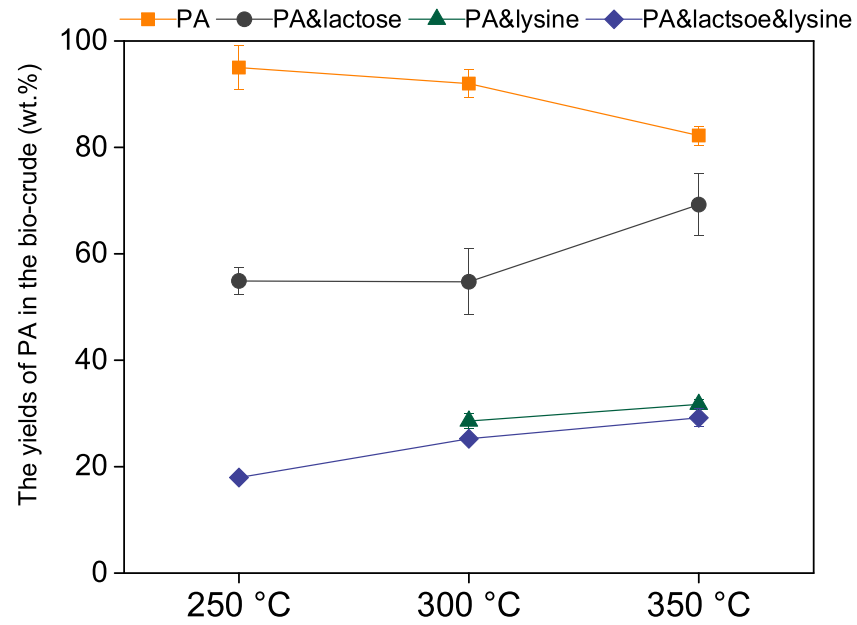

Fig. 6. Yields of palmitic acid in the bio-oil obtained from HTL of model compounds at different temperatures (bio-oil products from lysine mixed with PA at $250^{\circ} \mathrm{C}$ were not collected).

are also shown in Fig. 6. We can see that the bio-oil obtained from HTL of single PA is almost composed of unreacted PA, along with a slight decrease from 95 to $82 \mathrm{wt}$. \%, indicating that palmitic acid has a relatively high thermal stability and can be considered stable below $350^{\circ} \mathrm{C}$, although experiences show some degree of degradation under hydrothermal conditions to produce long-chain hydrocarbons by decarboxylation. This may possibly explain the negligible changes of the element content in the bio-oil phase as compared to different temperatures. Based on the relative high concentration of PA in the bio-oil (see TS5), here, in the cases of the binary mixture of lysine and PA, as well as the ternary mixture, the calculated $\mathrm{N}$ content in the bio-oil was defined as the total $\mathrm{N}$ mass divided by the remaining bio-oil mass (total bio-oil is excluded from the unreacted PA). As a result, the calculated $\mathrm{N}$ content in bio-oil obtained from lysine mixed with PA is 11.1 and $6.4 \%$ at 300 and $350^{\circ} \mathrm{C}$, respectively. In the case of the ternary mixture, from 250 to $350{ }^{\circ} \mathrm{C}$, the calculated $\mathrm{N}$ content is actually increased from 6.4 to $7.8 \%$. As an evidence of the dilution effect of PA on the $\mathrm{N}$ content, it is necessary to further confirm that the amidation enhances $\mathrm{N}$ transform into bio-oil.

When mixing lysine with palmitic acid, as described in Fig. 1 and shown in $\mathrm{S} 1$, at $250^{\circ} \mathrm{C}$, a stable emulsion of the bio-oil in the aqueous phase was formed, making it unrecoverable. When the reaction temperature increases, it becomes easier to separate and collect the bio-oil. As illustrated in Fig. 1, the yield of bio-oil is up to $47 \mathrm{wt} . \%$ at $350{ }^{\circ} \mathrm{C}$, and there is a great increase in palmitamide production (Fig. 4(c)). However, the binary-mixture nitrogen content in the bio-oil was dramatically decreased. This could be due to the dilution of nitrogen- containing species by palmitic acid and derivatives. The yields of PA from lysine and the PA increase with reaction temperature, nearly reaching $31.8 \mathrm{wt} . \%$ at $350^{\circ} \mathrm{C}$, can support that the lower $\mathrm{N}$ content in the bio-oil is partly owing to the dilution effect of a relatively higher fraction of PA remaining in the bio-oil. The only substituted long-chain aliphatic amide is found in the bio-oil and increased with reaction temperature, which is in line with findings by Chiaberge [23]. This can indicate a base reaction medium, in which the rate of amide formation or condensation is much faster than the hydrolysis rate of hexadecanamide. As an evidence, more ammonium was found to be distributed in water phase. In addition, it is interesting to see that the piperidine concentration is not only much higher than that in the reaction product from lysine alone, but also triple the yields of caprolactam (Fig. 4(c)), indicating that either intermediates generated from palmitic acid improve the cyclization of lysine, or the decomposition of caprolactam increases the piperidine yield directly.

With regard to the ternary mixture, the interaction between these compositions is more complex. As show in Fig. 4(d), an extremely low yield of pyrazines is produced and remains essentially constant; accordingly, a significant increase in amides indicates the strong competition between amidation and MRs. It has been reported that some lipid-Maillard products are produced by the interaction between lipid and Maillard precursors, as an evidence of long-chain heterocyclic compounds containing $\mathrm{N}$ or $\mathrm{S}$ was found when thiophene was mixed with pyrazines at $140^{\circ} \mathrm{C}$ [32]. This could be one reason to explain the suppression of Maillard reaction, even though in this work, no S-containing compounds are involved. Being in the same periodic group, $\mathrm{N}$ and S, however, can behave similarly in this case. It is likely that fatty acids and their free-radical degradation products compete with the sugar-derived carbonyl compounds to react with active amino groups or the amines formed during heating time to generate amides, thus interfering with the Maillard pathways, leading to a great suppression of pyrazines.

A possible second reason could be the occurrence of Mannich reactions between amines and formaldehyde in the presence of carbonyl functional groups [33]. During HTL, after more than a few minutes, lactose is easily converted into short-chain carboxylic acids as well as phenolic compounds, aldehydes, and ketones [22,34]. The intermediate nitrogen-containing compounds may have reacted with formaldehyde and phenols via Mannich reactions, forming solid products with high nitrogen contents, indicated by the higher nitrogen content of hydrochar from HTL of the ternary mixture when compared with the results from the lysine and PA mixture (see Table S6).

In addition, in the presence of lactose, the interactions between PA and lactose could generate short-chain carboxylic acids as intermediate products that increase acidity of the reaction medium, which further inhibits pyrazine production. This is in agreement with Koehler's work [31], where the addition of sulfuric acid reduced pyrazine formation to 


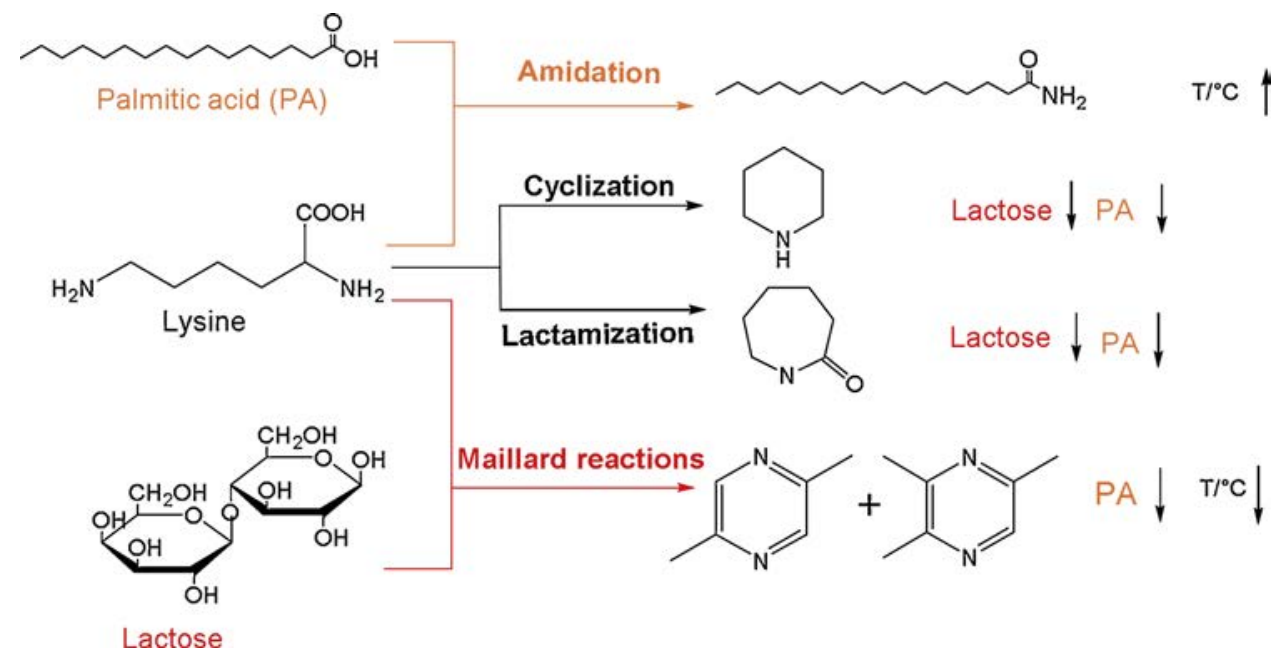

Fig. 7. Reaction network for the N-containing compounds obtained from HTL of model substances (the up and down arrows represent the increase and decrease in efficiency, respectively).

practically zero in a glucose-asparagine system. The overall high $\mathrm{NH}_{4}{ }^{+}$$\mathrm{N}$ in aqueous phase can be a proof that higher acidity promotes the deamination of amino acid or N-containing polar water-soluble organics, leading to a decrease in Maillard reaction products.

According to the results and discussion above, the possible reaction pathways that encompass the fate of nitrogen within the system can be proposed based on the model compounds' reaction network, as shown in Fig. 7.

\section{Conclusion}

The work presented here has provided a deeper understanding of the fate of $\mathrm{N}$ during HTL of complex biomasses based on a surrogate species system. The dramatic difference in the chemical composition of bio-oil by hydrothermal liquefaction confirmed that it is necessary to clarify the interaction between different organic compositions in the feedstocks. In all cases with the addition of lipid, nitrogen distribution in the bio-oil was enhanced due to the higher bio-oil yields. For the binary mixtures, adding lipid to amino acids improved the bio-oil yield and decreased the $\mathrm{N}$ content relative to the conversion of lysine alone. Amidation may explain the higher bio-oil yields and composition owing to the long-chain aliphatic fatty acid amide produced compared to HTL of single lysine. Regarding the ternary mixture, the addition of lipid largely modifies the type of $\mathrm{N}$-containing species in the final bio-oil, but does not affect the nitrogen content. With increasing temperature, the strong competition of amidation and MRs significantly impacts the fate of $\mathrm{N}$ in the bio-oil: pyrazines are decreased to less than $1 \mathrm{wt}$. \%, with a sustaining increase of palmitamide, suggesting that amidation is favored under hydrothermal conversion, while MRs are largely inhibited. In the current work, so far, only surrogate mixtures have been used; therefore, a further comparison with real samples is required to increase the reliability of identification.

\section{Author statement}

Y. Fan designed and performed the experiments, and analysed the data. Y. Fan wrote the manuscript in consultation with U. Hornung, K. Rafflet and N. Dahmen. U. Hornung and N. Dahmen supervised the project, and put efforts to correct the manuscript. All authors discussed the results and commented on the manuscript.

\section{Declaration of Competing Interest}

The authors declare no conflict of interest.

\section{Acknowledgments}

Armin Lautenbach, Birgit Rolli, Alexandra Böhm, Jessica Mayer, and Sonja Habicht are thanked gratefully for their skillful technical assistance. Thomas Tietz and Matthias Pagel are thanked for the mechanical support. The authors gratefully acknowledge the financial support from the China Scholarship Council.

\section{References}

[1] M. Déniel, G. Haarlemmer, A. Roubaud, E. Weiss-Hortala, J. Fages, Bio-oil production from food processing residues: improving the bio-oil yield and quality by aqueous phase recycle in hydrothermal liquefaction of blackcurrant (Ribes nigrum L.) Pomace, Energy Fuels 30 (2016) 4895, https://doi.org/10.1021/acs. energyfuels.6b00441.

[2] R. Posmanik, C.M. Martinez, B. Cantero-Tubilla, D.A. Cantero, D.L. Sills, M.J. Cocero, J.W. Tester, Acid and alkali catalyzed hydrothermal liquefaction of dairy manure digestate and food waste, ACS Sustain. Chem. Eng. 6 (2018) 2724 https://doi.org/10.1021/acssuschemeng.7b04359.

[3] B. Guo, V. Walter, U. Hornung, N. Dahmen, Hydrothermal liquefaction of Chlorella vulgaris and Nannochloropsis gaditana in a continuous stirred tank reactor and hydrotreating of biocrude by nickel catalysts, Fuel Process. Technol. 191 (2019) 168, https://doi.org/10.1016/j.fuproc.2019.04.003.

[4] D. López Barreiro, M. Beck, U. Hornung, F. Ronsse, A. Kruse, W. Prins, Suitability of hydrothermal liquefaction as a conversion route to produce biofuels from macroalgae, Algal Res. 11 (2015) 234, https://doi.org/10.1016/j.algal.2015.06.023.

[5] S. Itoh, A. Suzuki, T. Nakamura, S.-y. Yokoyama, Production of heavy oil from sewage sludge by direct thermochemical liquefaction, Desalination 98 (1994) 127, https://doi.org/10.1016/0011-9164(94)00137-5.

[6] M. Paneque, J.M. De la Rosa, J. Kern, M.T. Reza, H. Knicker, Hydrothermal carbonization and pyrolysis of sewage sludges: what happen to carbon and nitrogen? J. Anal. Appl. Pyrolysis 128 (2017) 314, https://doi.org/10.1016/j.jaap.2017.09.019.

[7] D.C. Elliott, P. Biller, A.B. Ross, A.J. Schmidt, S.B. Jones, Hydrothermal liquefaction of biomass: developments from batch to continuous process, Bioresour. Technol. 178 (2015) 147, https://doi.org/10.1016/j.biortech.2014.09.132.

[8] J. Ramirez, R. Brown, T. Rainey, A review of hydrothermal liquefaction bio-crude properties and prospects for upgrading to transportation fuels, Energies 8 (2015) 6765, https://doi.org/10.3390/en8076765.

[9] F. Obeid, T. Chu Van, R. Brown, T. Rainey, Nitrogen and sulphur in algal biocrude: A review of the HTL process, upgrading, engine performance and emissions, Energy Convers. Manage. 181 (2019) 105, https://doi.org/10.1016/j.enconman.2018.11. 054.

[10] P. Duan, P.E. Savage, Hydrothermal liquefaction of a microalga with heterogeneous catalysts, Ind. Eng. Chem. Res. 50 (2011) 52, https://doi.org/10.1021/ie100758s.

[11] L. Qian, S. Wang, P.E. Savage, Hydrothermal liquefaction of sewage sludge under isothermal and fast conditions, Bioresour. Technol. 232 (2017) 27, https://doi.org/ 10.1016/j.biortech.2017.02.017.

[12] B. Zhao, Z. Shi, X. Yang, Upgrading algae biocrude for a low-nitrogen-containing 
biofuel: compositions, intermediates, and reaction routes, Ind. Eng. Chem. Res. 56 (2017) 6378, https://doi.org/10.1021/acs.iecr.7b01405.

[13] M. Haider, D. Castello, K. Michalski, T. Pedersen, L. Rosendahl, Catalytic hydrotreatment of microalgae biocrude from continuous hydrothermal liquefaction: heteroatom removal and their distribution in distillation cuts, Energies 11 (2018), https://doi.org/10.3390/en11123360.

[14] C.C. Schmitt, K. Raffelt, A. Zimina, B. Krause, T. Otto, M. Rapp, J.-D. Grunwaldt, N. Dahmen, Hydrotreatment of fast pyrolysis bio-oil fractions over nickel-based catalyst, Top. Catal. 61 (2018) 1769, https://doi.org/10.1007/s11244-018-1009-z.

[15] M. Saidi, F. Samimi, D. Karimipourfard, T. Nimmanwudipong, B.C. Gates, M.R. Rahimpour, Upgrading of lignin-derived bio-oils by catalytic hydrodeoxygenation, Energy Environ. Sci. 7 (2014) 103, https://doi.org/10.1039/ c3ee43081b.

[16] G. Teri, L. Luo, P.E. Savage, Hydrothermal treatment of protein, polysaccharide, and lipids alone and in mixtures, Energy Fuels 28 (2014) 7501, https://doi.org/10 1021/ef501760d.

[17] R. Posmanik, D.A. Cantero, A. Malkani, D.L. Sills, J.W. Tester, Biomass conversion to bio-oil using sub-critical water: study of model compounds for food processing waste, J. Supercrit. Fluids 119 (2017) 26, https://doi.org/10.1016/j.supflu.2016. 09.004.

[18] A. Kruse, P. Maniam, F. Spieler, Influence of proteins on the hydrothermal gasification and liquefaction of biomass. 2. Model compounds, Ind. Eng. Chem. Res. 46 (2007) 87, https://doi.org/10.1021/ie061047h.

[19] G.B. Naranjo, A.S. Pereyra Gonzales, G.E. Leiva, L.S. Malec, The kinetics of Maillard reaction in lactose-hydrolysed milk powder and related systems containing carbohydrate mixtures, Food Chem. 141 (2013) 3790, https://doi.org/10.1016/j. foodchem.2013.06.093.

[20] C. Zhang, X. Tang, L. Sheng, X. Yang, Enhancing the performance of Co-hydrothermal liquefaction for mixed algae strains by the Maillard reaction, Green Chem. 18 (2016) 2542, https://doi.org/10.1039/c5gc02953h.

[21] W. Yang, X. Li, Z. Li, C. Tong, L. Feng, Understanding low-lipid algae hydrothermal liquefaction characteristics and pathways through hydrothermal liquefaction of algal major components: crude polysaccharides, crude proteins and their binary mixtures, Bioresour. Technol. 196 (2015) 99, https://doi.org/10.1016/j.biortech. 2015.07.020.

[22] Y. Fan, U. Hornung, N. Dahmen, A. Kruse, Hydrothermal liquefaction of proteincontaining biomass: study of model compounds for Maillard reactions, Biomass Convers. Biorefinery 8 (2018) 909, https://doi.org/10.1007/s13399-018-0340-8.

[23] S. Chiaberge, I. Leonardis, T. Fiorani, G. Bianchi, P. Cesti, A. Bosetti, M. Crucianelli,
S. Reale, F. De Angelis, Amides in bio-oil by hydrothermal liquefaction of organic wastes: a mass spectrometric study of the thermochemical reaction products of binary mixtures of amino acids and fatty acids, Energy Fuels 27 (2013) 5287, https://doi.org/10.1021/ef4009983.

[24] H. Li, Z. Liu, Y. Zhang, B. Li, H. Lu, N. Duan, M. Liu, Z. Zhu, B. Si, Conversion efficiency and oil quality of low-lipid high-protein and high-lipid low-protein microalgae via hydrothermal liquefaction, Bioresour. Technol. 154 (2014) 322, https://doi.org/10.1016/j.biortech.2013.12.074.

[25] J. Yang, Q. He, L. Yang, A review on hydrothermal co-liquefaction of biomass, Appl. Energy 250 (2019) 926, https://doi.org/10.1016/j.apenergy.2019.05.033.

[26] S. Raikova, T.D.J. Knowles, M.J. Allen, C.J. Chuck, Co-liquefaction of macroalgae with common marine plastic pollutants, ACS Sustain. Chem. Eng. 7 (2019) 6769, https://doi.org/10.1021/acssuschemeng.8b06031.

[27] J. Wang, X. Peng, X. Chen, X. Ma, Co-liquefaction of low-lipid microalgae and starch-rich biomass waste: the interaction effect on product distribution and composition, J. Anal. Appl. Pyrolysis 139 (2019) 250, https://doi.org/10.1016/j.jaap. 2019.02.013.

[28] S. Tang, Z. Shi, X. Tang, X. Yang, Hydrotreatment of biocrudes derived from hydrothermal liquefaction and lipid extraction of the high-lipid Scenedesmus, Green Chem. 21 (2019) 3413, https://doi.org/10.1039/c9gc00673g.

[29] M.P. Caporgno, E. Clavero, C. Torras, J. Salvadó, O. Lepine, J. Pruvost, J. Legrand, J. Giralt, C. Bengoa, Energy and nutrients recovery from lipid-extracted nannochloropsis via anaerobic digestion and hydrothermal liquefaction, ACS Sustain. Chem. Eng. 4 (2016) 3133, https://doi.org/10.1021/acssuschemeng.6b00151.

[30] M. Watanabe, T. Iida, H. Inomata, Decomposition of a long chain saturated fatty acid with some additives in hot compressed water, Energy Convers. Manage. 47 (2006) 3344, https://doi.org/10.1016/j.enconman.2006.01.009.

[31] P.E. Koehler, G.V. Odell, Factors affecting the formation of pyrazine compounds in sugar-amine reactions, J. Agric. Food Chem. 18 (1970) 895, https://doi.org/10. 1021/jf60171a041.

[32] L.J. Farmer, Flavor-Food Interactions, American Chemical Society, 1996, p. 48 Chapter 5.

[33] X. Chen, X. Peng, X. Ma, J. Wang, Investigation of Mannich reaction during coliquefaction of microalgae and sweet potato waste, Bioresour. Technol. 284 (2019) 286, https://doi.org/10.1016/j.biortech.2019.03.136.

[34] J. Remón, M. Laseca, L. García, J. Arauzo, Hydrogen production from cheese whey by catalytic steam reforming: preliminary study using lactose as a model compound, Energy Convers. Manage. 114 (2016) 122, https://doi.org/10.1016/j.enconman. 2016.02.009. 
Karlsruher Institut für Technologie

\section{Repository KITopen}

Dies ist ein Postprint/begutachtetes Manuskript.

Empfohlene Zitierung:

Fan, Y.; Hornung, U.; Raffelt, K.; Dahmen, N.

The influence of lipids on the fate of nitrogen during hydrothermal liquefaction of proteincontaining biomass.

2020. Journal of analytical and applied pyrolysis, 147.

doi: $\underline{10.5445 / I R / 1000117645}$

Zitierung der Originalveröffentlichung:

Fan, Y.; Hornung, U.; Raffelt, K.; Dahmen, N.

The influence of lipids on the fate of nitrogen during hydrothermal liquefaction of proteincontaining biomass.

2020. Journal of analytical and applied pyrolysis, 147, Art. Nr.: 104798.

doi:10.1016/j.jaap.2020.104798

Lizenzinformationen: $\underline{\text { C B BY-NC-ND } 4.0}$ 